\title{
Evaluation of Residence Time of Dust Aerosols during the Harmattan Season in Sokoto Area of Northwestern Nigeria, Using Visibility Data
}

\author{
J. O. Akande ${ }^{1}$, M. Momoh ${ }^{2}$ I.G. Saidu ${ }^{3}$, M.I. Ilyasu ${ }^{3}$, D.O. Akpootu ${ }^{2}$, \\ M.B Abubakar ${ }^{3}$ and M. B. Abdullahi ${ }^{2}$ \\ ${ }^{1}$ Department of Physics, Federal College of Education (Tech), Gusau Zamfara State, Nigeria \\ ${ }^{2}$ Department of Physics, Usmanu Danfodio University, Sokot Sokoto State, Nigeria \\ 3 Physics Unit, Sokoto State Polytechnic Sokoto
}

\begin{abstract}
Sokoto $\left(13.01^{0} \mathrm{~N}, 5.15^{\circ} \mathrm{E}\right)$ lies within the hot /dry semi desert climate type i.e. Sahel Savannah climate zone and is identified as one of the regions in West Africa that is severely affected by the dust particles originating from Sahara desert. In this paper, we computed the residence time of dust aerosol in Sokoto region using visibility data for 20 years (1991-2010) obtained from Nigeria Meteorological Agency (NIMET). The method used yielded results which show variations in the values of the monthly and annual mean residence time of values 2.4-12.9 and 5.21 days respectively for the Harmattan months (November to March). These values are in general agreed with measurable values and similar to other naturally occurring aerosols in the atmosphere. Reasons are adduced for the variations.
\end{abstract}

Keywords: Dust aerosols, Harmattan, Residence time, Visibility

\section{Introduction}

The presence of dust aerosol in the atmosphere during the harmattan season in the northern hemisphere is a familiar feature of the climate of most parts of West Africa. The dust aerosol are mobilized by wind erosion processes from the Sahara and Sahel regions of West Africa and transported down by the prevailing North Easterly Trade Wind. According to the facts established by many researchers, the harmattern haze, a natural atmospheric aerosol regime which affects most parts of West Africa including Nigeria has its origin in the Sahara desert in North East Africa. For instance Kalu[1], Prospero,[2],Babatunde et al [3] identify the alluvial plain of Bilma $\left(18^{\circ} \mathrm{N}, 12^{0} \mathrm{E}\right)$ in Southern Niger, and Largeau $\left(18^{0} \mathrm{~N}, 19^{\circ} \mathrm{E}\right)$, in Chad as the main sources of the dust which affects the greater parts of West Africa. Kalu[1] reported that during desert storms, large quantity of sand and dust are lifted into the atmosphere, transported by the North East trade winds and dispersed throughout West Africa from the month of November of one year to March of the following.

According to Papastefanou and Bondnetti[4] and Gong et[5] the residence time of aerosol in the atmosphere is a function of various removal processes, the most important being: (a) dry deposition by impaction, diffusion and sedimentation and (b) wet deposition by raindrops as a result of processes occurring both within and below the rain cloud. They further asserted that there could be variations in the removal rates at different continental locations of the globe, over the oceans, and at high altitudes of the atmosphere due to changes in meteorological conditions. Martell [6] and Kuroda[7] reported that several methods have been used for estimating the mean residence times of atmospheric aerosols which include measurements of the radioactivities and ratios of: (a) fission products from nuclear weapons tests, (b) cosmic ray-produced radionuclides and (c) $222 \mathrm{Rn}$ and $22^{\circ} \mathrm{Rn}$ decay products. However, there is disagreement between the derived values of the residence times due to the various processes, including the fact that they refer to different portions of the atmosphere (e.g. cosmic ray-produced isotopes refer to the upper troposphere and radon daughters to lower troposphere, etc.) and also due to the existence of different sources for some isotopes.

In the atmosphere, the aerosol is acted upon by various processes like coagulation, sedimentation, wash out and rain out. These processes affect the lifetime of the aerosols in the atmosphere. According to Rajan [8], at steady state, the residence time of an aerosol system could be defined as the ratio of their concentration present at that time to the production/loss rate.

The potential impacts of aerosol loading and the associated desert encroachment have necessitated continuous monitoring of aerosol concentration. The environmental implication of monitoring aerosol concentration particularly in industrialized cities and urban environment cannot be over emphasized as Retalis, et al [9] stated that concentrated aerosols from substances from substances such as silica, asbestos and diesel 
particulate are sometimes found in the workplace and have been shown to result in a number of diseases including respiratory failures, black lung and ecological stress. Suspended dust particles in the atmosphere affects local and regional air quality and therefore impact on human health. According to reports, the presence of the harmattan dust is often generally associated with the seasonal outbreak of cerebrospinal meningitis (CSM), for Afeti and Resch[10] wrote that twice as many cases of CSM during the harmattan period compared to the rest of the year was reported in Ghana. Similarly Isezuo[11] found that the peak of hospital admission for hypertension-related morbidities corresponded with the occurrence of high dust concentration in Sokoto.

The atmospheric aerosol has a profound effect on our lives. It affects global climate, local weather, visibility and personal health. Hence, scientists are much interested in undertaking studies to understand the way aerosol affect regional and global climate. We need frequent global observation of cloud and aerosol properties to help us gain better understanding of how they interact with one another. The main purpose of this study is to compute the residence time of dust aerosol during the harmattan seasons using visibility data for twenty harmattan seasons. From available records in Nigeria, this is the first attempt to compute the residence time of dust aerosol using visibility. .

\section{Measurement Of Atmospheric Aerosol Concentration}

The devices used for the study of atmospheric aerosol range from simple instruments such as Handheld Sun-Photometer for measurement of light transmission or porous filters to collect material for determining the mass concentration to very sophisticated sensors or collectors like impactor to characterize the particle size distribution. Rajan [8] has given a review of different experiment techniques used in aerosol studies. According to him, the measurement of aerosol characteristics can be done by remote sensing techniques from the ground and from satellites or by in situ measurements from ground or air borne instruments. Remote sensing techniques employ electromagnetic energy as the means of detecting and measuring target characteristics. They have the advantage of sensing the aerosols in its natural condition and provide information for the entire aerosol system and over a large area (from satellites). But the disadvantage is that it does not measure the aerosol characteristics directly but infers them from the optical characteristics. In situ measurements or direct measurements give information about the aerosol parameters at their location in real time. But the disadvantage is that they are performed in a .local volume or area and suffer from inherent problems, such as heating of the aerosol during collection and variable collection efficiency.

In this study however, visibility data is been employed as a means of accessing the level of dust aerosol concentration in the study location. The use of visibility and other meteorological data has been the traditional approach use by meteorologists for forecasting dust weather. For instance, Kalu [1] and Adebayo [12] used visibility data to establish the trajectory of dust over West Africa, while N'Tchayi Mbourou et al [13] used visibility data from 53 stations to investigate the diurnal and spatial seasonal variability of dust over North Africa.

\section{Data and Methodology}

Sokoto $\left(13.07^{0}, 5.23^{0}\right)$ lies within the hot/dry semi desert climate type i.e within the Sahel climate region. The climate alternate between the dry season and the rainy season. The dry season begins around November/October to March, when the North-easterly winds from Sahel dominates the climate pattern. Between April and November, the climate is dominated by the South-westerly winds from the Atlantic.

The data used in this study are derived from the Nigeria Meteorological Agency (NIMET), Sokoto Airport in collaboration with their operational base in Lagos. The Agency maintains a network of synoptic stations at various locations in Nigeria. These stations measures hourly values of various meteorological data on a continuous basis in accordance with standard procedure specified by the World Meteorological Organisation (WMO). Monthly average visibility data obtained from daily mean data are used to analyze the variability in visibility and hence atmospheric dust loading for a period of 20 years from 1991 to 2010. The visibility data is then used to calculate the mean monthly residence time from which the yearly or seasonal average is determined.

The residence time, $\tau$ of dust aerosol is dynamically calculated according to the formula proposed by Gong et al [5] given as:

$$
\tau=\frac{\mathrm{V}_{\mathrm{x}}}{\left[\mathrm{dv}_{\mathrm{x}} / \mathrm{dt}\right]}
$$

where $\mathrm{V}_{\mathrm{x}}$ represent the visibility in meters $(\mathrm{m})$ for the season and $[\mathrm{dv} / \mathrm{dt}]$ is the time rate of change in visibility in meters per day $\left(\right.$ mday $\left.^{-1}\right)$ during the season which is due to increase or decrease in visibility. . 


\section{Results and Discussion}

The main purpose of this study was to investigate the pattern of visibility in Sokoto and use it to determine the mean residence time of dust aerosol in Sokoto area. . Table 1 shows the summary of the calculations of the residence time in days calculated for each month and the average for each harmattan season and figure 1 shows the variation of the annual mean residence time for the 20 years harmattarn seasons

Table 1: Showing the monthly and the mean residence time $\tau$ in days for each of the Harmattan seasons.

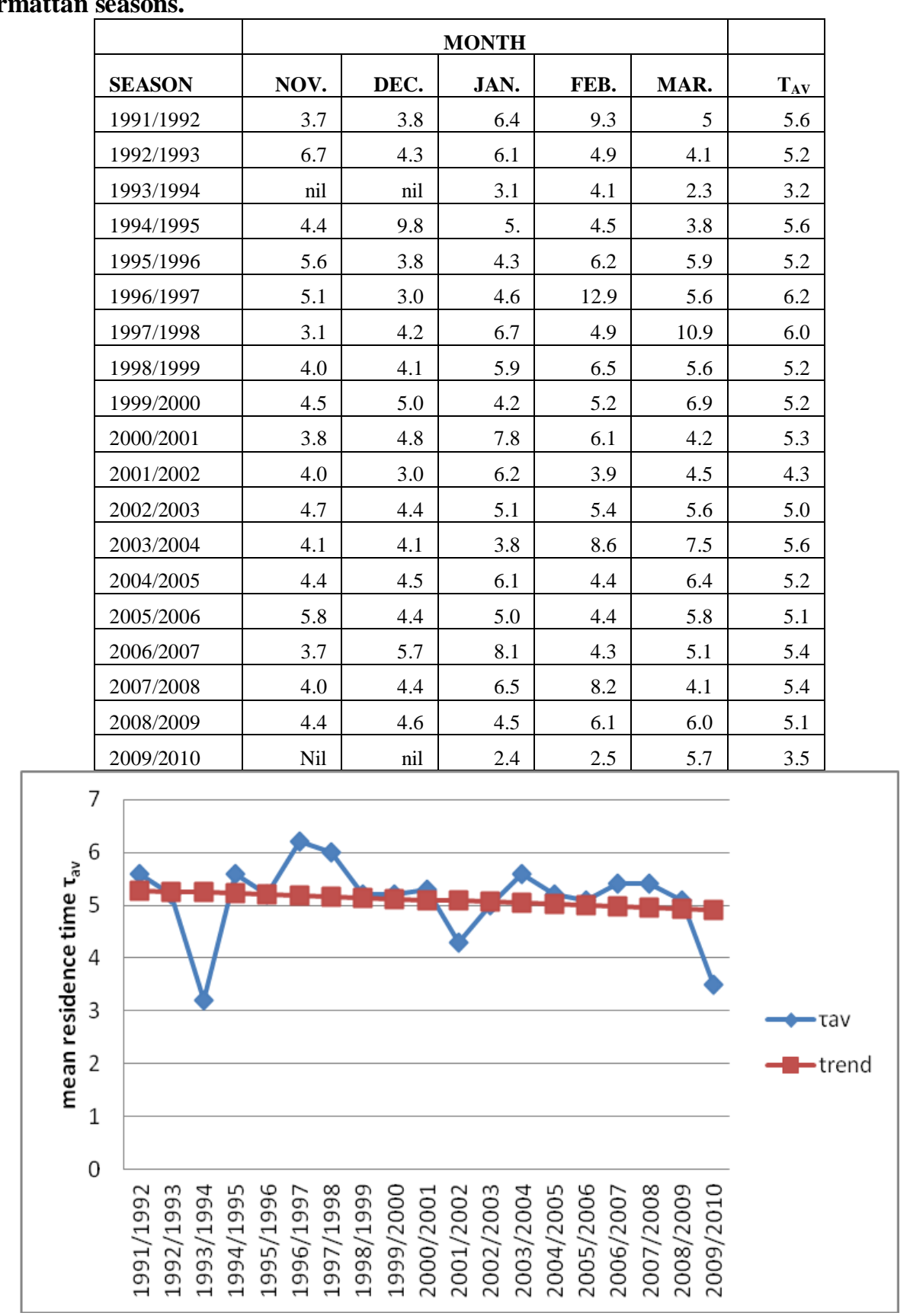

Fig. 1: Variability of harmattan season residence time of dust aerosol in Sokoto (1991-2010)

The result of the analysis shows random variations in the values of the residence times among the Harmattan season months (November to March) and also seasonally. Nevertheless, there appear to be a slight downward trend between 1991 to 2010 . The linear trend is given by a straight line equation $\tau=-0.02 x+5.30$ (where $\tau$ is residence time in days and $\mathrm{x}$ is the season number taken to be 0 for the base season 1990/91). The annual mean residence time for the twenty years period is calculated to be 5.21 days, while the monthly values ranged between 2.4 to 12.9 days. From the result obtained for the months of February 1997 and March 1998, it means that the dust aerosol stayed comparatively longer in the lower atmosphere before disappearance probably 
due to some unusual meteorological conditions prevailing at that time. This is because Kalu[1]mentioned wind, temperature and relative humidity as some of the important characteristics of the atmosphere that control the propagation of Sahara dust. He explained that the prevailing wind plays the greatest role in the movement of Sahara dust and that light winds and calm conditions are very conducive for longer persistence periods for a dusty atmosphere than stronger winds. That a high moisture content or humidity is not conducive for dust to persist for long in the atmosphere as large amount of it would sediment out giving rise to improved visibility. Therefore, the variations in the values obtained may be attributed to the variations in the prevailing conditions particularly wind, relative humidity and temperature. The values obtained for the residence time of dust aerosol in this location, using our method fall within the range of few measurements available [4, 14]. For instance Papastefanou and Bondietti [4] obtained values of residence time which ranged between 4.8 and 15.3 days with an average of 8.2 days in Oak Ridge Tennessee while Uematsu et al [14] obtained an estimated value of atmospheric residence times determined from Chernobyl radioactivity over the North Pacific to be 3-5 days. The discrepancy between these reported values and what is obtained in our own work is due to the fact that the removal processes of the aerosols and the method employed in determining them are not the same and also while the others referred to radioactive materials, ours referred to dust aerosols.

\section{Conclusion}

The result obtained using our method shows random variations in the values of the mean residence time both in the harmattan season months of November to March and annually throughout of the twenty harmattan seasons (1991-2010). The respective values of 2.4-12.9 and 5.21 days are in agreement with those obtained using different methods and in different locations in the globe. The result also shows a slight downward trend in the values of annual mean residence time in twenty years period.

\section{References}

[1] Kalu, A.E. The African dust plume, its characteristics and propagation across West inwinter. Sahara Dust mobilization,Transport Deposit Scope 14, John Willy(1979) pp. 95-118.

[2] Prospero, J.M. Long range transport of mineral dust in the Global Atmosphere: Impact of African Dust on the Environment of SouthEastern United States, Proc.Nat Acad Sci., U.S.A. 96(7),(1999) 3396-3403.

[3] Babatunde, E.E. Akoshile, C.O Garnesh, SWilloughby,A.A Ajibola, T.B Falaiye, O.A, Adimula, I.A Aro, T.O Observation bioeffect of SW-global solar radiation in Ilorin in the tropics. Adv.Space Res.43(2008) 990-994.

[4] Papastefanou. C and Bondietti, E.A Mean Residence times of Atmospheric Aerosols in the boundary layer as determined from ${ }^{210} \mathrm{Bi} /{ }^{210} \mathrm{~Pb}$ Activity Ratios. J. Aerosol Sci. vol.12 No 7 .(1991) Pp 927-43.

[5] Gong, S.L Barrie, L.A and Blanchet, J.P.Modeling sea-salt aerosols in the atmosphere1.Journal of Geophysical Research.Vol.102,No.D3 (1997),pp 3805 -3818.

[6] Martell, E.A Transport patterns and residence times for Atmospheric trace constituents vs altitudes. In Radionuclides in the Environment, ACS Syrup. Set. No. 93(1970) pp. 138-157. American Chemical Society, Washington DC

[7] Kuroda, P. K Use of radioactive isotopes as atmospheric tracers. In Applications of Nuclear and Radiochemistry (Edited by Lambrecht, R. M. And Morcos, N.) (1982) pp.457-481. Pergamon Press, New York.

[8] Rajan, R An Introduction to Atmospheric Aerosol system. Mahatma University Kottayam (2010) pp 12-17,18-20, 30-36.

[9] Retalise, A Hadjimitsis, D.G, Michaelides S, .Tymvios, F Chrysonlakis, N Clayton, C.R.I and Themistocleous, K .Comparison of aerosol optical thickness with in situ visibility data over Cyprus, Nat. Hazards Earth Syst.Sci.10 (2010) 421-428.

[10] Afeti, G.M and Resch, F.J. Physical characteristics of Saharan dust near Gulf of Guinea .Atmospheric Environment34,(2000)12731279 .

[11] Isezuo, S.A. Seasonal variation in hospitalization For hypertension- related morbidities in Sokoto, north-western Nigeria. International journal of Circumpolar Health 62 (4),(2003) 397, 409

[12] Adebayo, S .I..Trajectories of advected Sahara dust in Nigeria. AtmosphericEnvironment 2 (7) (1989) 1581 - 1589.

[13] N'Tchayi, G. M., Bertrand, J. J and Nicholas, S The Diurnal and SeasonCycles of Wind -Borne Dust over Africa North of Equator". J Appl. Meteorology 36,(1996) pp868-882.

[14] Uematsu, M Merrill, J.T. Patterson, T.L Duce, R.A. and Prospero. J. M AerosolResidence times and Iodine gas/particle conversion over North Pacific as determinedfrom Chernobyl radioactivity. Geochemical journal. Vol. 22 (1988) pp 157-163 